
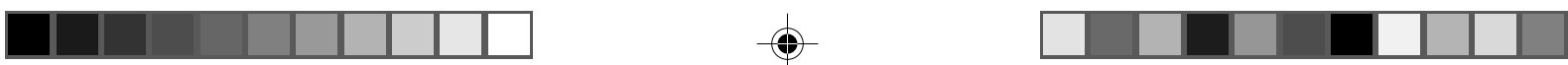

\title{
No interior da floresta, a necessidade por deslocamentos: o caso dos bondes em Manaus
}

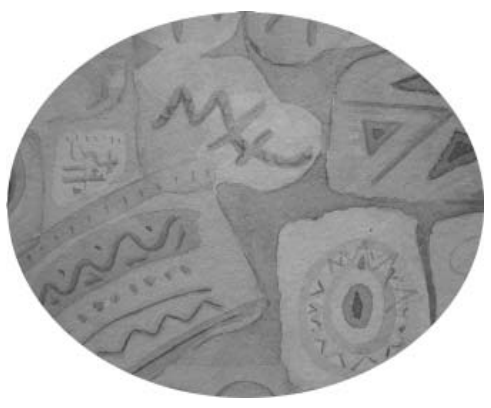

Soraia Pereira Magalhäes*

\section{Resumo}

Este artigo procura apresentar dados sobre a trajetória dos bondes em Manaus desde sua implantação em 1896 até 1957, quando esses veículos foram definitivamente retirados de circulação. No estudo, podemos enveredar por vários momentos da vida urbana da cidade e das ações do poder público em torno dos deslocamentos no segmento dos transportes coletivos.

Palavras-chave: Bondes em Manaus. Transporte coletivo urbano.

\section{Abstract}

This article aims to introduce data of the history of the streetcars in Manaus, from its outset in 1896 to 1957, when these vehicles were definitively withdrawn from circulation. In this study we can explore various moments of the city's urban life and the actions taken by the government in matters related to public transportation in Manaus.

Keyword: Manaus streetcars. Urban Public Transportation.

Keywords: Manaus streetcars. Urban Public Transportation.

Este trabalho consiste numa síntese de informações originadas a partir da elaboração de minha dissertação de mestrado, defendida em janeiro de 2004, junto

\footnotetext{
" Bacharel em Biblioteconomia pela Universidade Federal do Amazonas. Mestra em Sociedade e Cultura na Amazônia pela Universidade Federal do Amazonas. E-mail: soraia.mag@gmail.com 
ao Programa de Pós-Graduação em Sociedade e Cultura na Amazônia, da Universidade Federal do Amazonas. Seu desenvolvimento teve entre outros aspectos, o objetivo de empreender uma investigação acerca do transporte coletivo de Manaus, visando acompanhar a dinâmica que orientou sua trajetória histórica e, consequentemente, à ação do poder público em Manaus para o desenvolvimento desse setor.

Tendo em vista que a ideia inicial desse estudo se deu por meio da localização e sistematização de fontes históricas relacionadas à temática em questão, ao longo do processo, percebi que a profundidade envolta nas informações apontava a composição das fontes documentais como recurso essencial para a compreensão de diversificados aspectos da dinâmica da cidade, fossem estas fontes oficiais ou produzidas pela imprensa. Dessa forma e, em se tratando do transporte coletivo, detalhes como datas de implantação, empresas atuantes, itinerários, quantidade de carros, quadro de horários, pontos de parada, entre outros, constituíram-se em material relevante e substancial para que pudéssemos traçar considerações sobre os serviços e as ações ocorridas neste segmento urbano em Manaus no período entre 1896 a 1980. Do decorrer ao término do processo de pesquisa de campo, o volume documental coletado atingiu o montante de 1.904 fontes primárias, que foram então distribuídas entre: documentação produzida pela imprensa (registros de jornais), documentação oficial (leis, decretos, mensagens, relatórios e projetos) e documentação iconográfica, material que nos permitiu traçar um plano de periodização para a abordagem de estudos do transporte coletivo urbano de Manaus, estabelecendo como pontos de partida quatro fases que discorrem sobre os seguintes pontos: os bondes (1896-1946), os ônibus de madeira (1947-1957), a Transportamazon (1957-1969) (empresa estatal gerenciada pelo poder público) e as primeiras empresas de transportes coletivos de Manaus (1967-1980) surgidas a partir do advento da Zona Franca. No que se refere a este texto apresento um apanhado sintético de informações que compõe o primeiro capítulo da dissertação e que corresponde à trajetória dos bondes e sua relação com a dinâmica da cidade.

\section{Deslocar é preciso: bondes elétricos para Manaus}

Desde o período provincial já vinham sendo discutidas as vantagens que os serviços realizados por bondes exerciam no desempenho das modernas sociedades, sendo desse período a aprovação da Lei n. ${ }^{\circ} 595$ de 1882 , que autorizava

96 Somanlu, ano 9, n. 1, jan./jun. 2009 

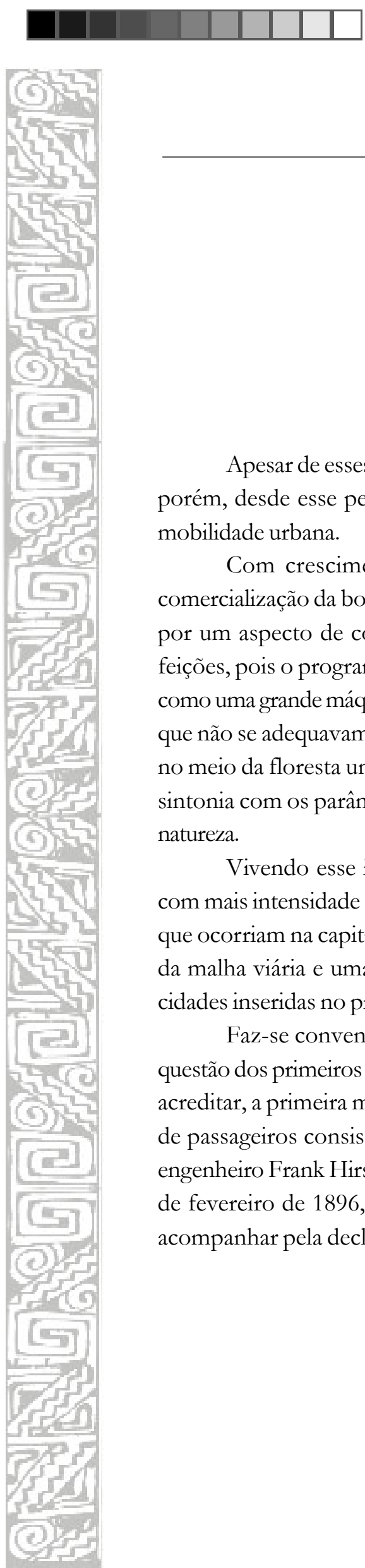

MIOLO Somanlu atual.pmd mobilidade urbana. natureza.

o presidente da Província a contratar a empresa paraense Almeida \& Fialho ou outra interessada, para a instalação de um completo sistema de transporte de viação movido por tração animal com "carros americanos sobre trilhos railhways sobre trilhos de sistema Bourgois para carga e passageiros." (COLLEÇÃO DE LEIS, 1882, p. 90.)

Apesar de esses serviços não terem sido implantados, tal iniciativa demonstra, porém, desde esse período a preocupação do poder público com os aspectos da

Com crescimento acelerado a partir de 1890, advindo das receitas da comercialização da borracha no mercado internacional, Manaus passou a se destacar por um aspecto de cosmopolitismo, desarmonizada, porém, de suas verdadeiras feições, pois o programa modernizador não respeitou aspectos regionais, passando como uma grande máquina, aterrando igarapés, ampliando ruas, edificando construções que não se adequavam nem ao clima, nem à cultura dos habitantes locais, moldando no meio da floresta uma cidade com arquitetura europeia que vislumbrava estar em sintonia com os parâmetros de modernidade, destoando, porém, de sua posição na

Vivendo esse ideal de modernidade e progresso, Manaus passou a buscar com mais intensidade a implementação dos serviços de locomoção, num período em que ocorriam na capital, além das intervenções urbanísticas e sanitárias, a ampliação da malha viária e uma série de outros investimentos que a colocariam no rol das cidades inseridas no processo modernizador.

Faz-se conveniente, porém, esclarecer um dado importante que circunda a questão dos primeiros bondes em Manaus, pois, ao contrário do que se convencionou acreditar, a primeira modalidade de veículos empregados para o transporte coletivo de passageiros consistiu em locomotivas de tração a vapor, que implantadas pelo engenheiro Frank Hirst Heblethwaite, foram inauguradas de forma provisória em 24 de fevereiro de 1896, na administração de Eduardo Ribeiro, conforme podemos acompanhar pela declaração do próprio governador:

Apraz-me communicar-vos que está inaugurado o serviço de viação pública do perímetro urbano da capital para os subúrbios [...]. O serviço provisório inaugurado a 24 de fevereiro, limita-se presentemente aos trechos compreendidos, na Estrada Epaminondas, entre a Praça Uruguayana e 5 de 
Setembro e entre esta e o Igarapé do Baptista naquella Estrada e o Cemitério São João do Alto no Mocó. [...] As tabelas de passagens, fretes e do horário para o tráfego provisório estão approvadas pelo governo [...]. O concessionário dentro do praso de oito meses substituirá todo o actual material rodante por outro d'accordo com o progresso da sciencia e das artes. [...]. (MENSAGEM, 1897, p. 28).

As empresas responsáveis pelos serviços de viação urbana em Manaus foram ambas de origem inglesa. A primeira a exercer o controle dos serviços foi a Manáos Railway Company, em 1898, e, posteriormente, a Manáos Tramways, a partir de 1908. Por meio dos incentivos despendidos pelo Estado para instalação e execução das atividades no campo da locomoção, a Manáos Railway não conseguiu atender aos serviços de maneira eficiente, recebendo duras críticas advindas do próprio governador Fileto Pires, que, após a aplicação de multas e da suspensão imposta a esta concessionária, assegurou que "o serviço era muito irregular e mantinha-se péssimo". (PIRES, 1898, p. 33.)

No que se refere ao desempenho dos serviços, não só o poder público cobrava melhor atuação dessa empresa, como também os jornais publicavam muitas reclamações relatando as irregularidades nos serviços. Da imprensa, uma das mais antigas informações sobre os serviços consiste em uma pequeníssima nota datada de 26 de outubro de 1899, publicada no jornal Comércio do Amaz̧onas, em que se lê: "pelo chefe de segurança foi requisitado uma força para policiamento dos bonds. Ora graças". (COMÉRCIO DO AMAZONAS, 1899). Não deixa claro o porquê da necessidade desta interferência policial, entretanto, é possível que nem todos fossem bem-vindos nas viagens por bondes, fossem estes mendigos, menores abandonados, prostitutas e outros.

Acompanhando a tipologia das reclamações registradas pela imprensa sobre a situação dos transportes por bondes em 1900, concluímos que o índice de insatisfação, a exemplo do que ocorre nos dias atuais, era o mesmo, pois as queixas destacavam mau atendimento prestado por funcionários, falta de troco, irregularidade de horários e, ainda, condições de desgaste dos veículos, sendo os maiores problemas, no entanto, relacionados ao comportamento inadequado dos funcionários, que, desrespeitando usuários, causavam justificadas críticas que os jornais reproduziam constantemente.

98 Somanlu, ano 9, n. 1, jan./jun. 2009 


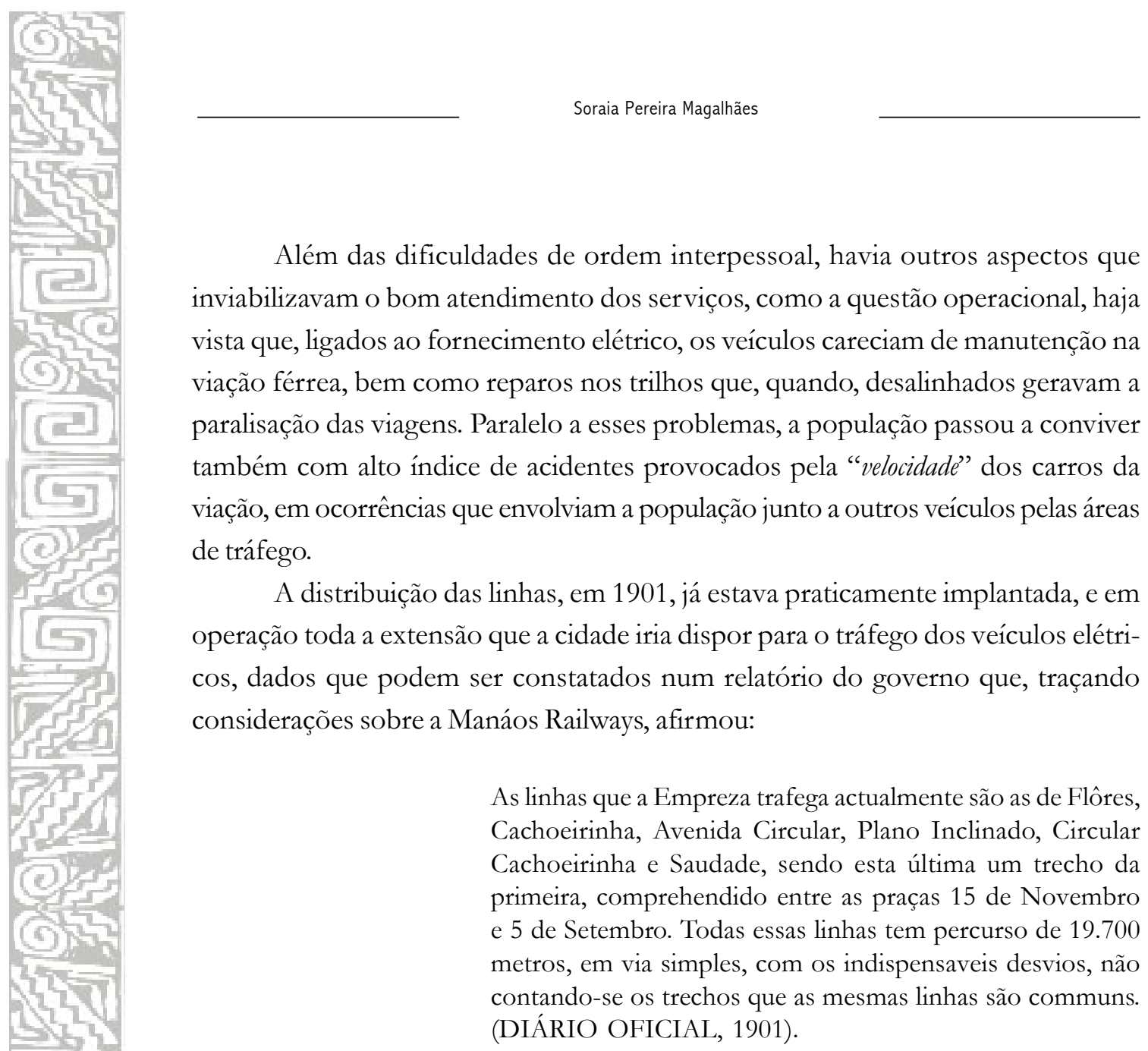

Esses veículos faziam o atendimento à população que, ao longo de 1900, foi superior a 50.000 habitantes, com uma frota de veículos que provavelmente atendera à demanda, tirando as dificuldades operacionais e de relações interpessoais. Os veículos que compunham a frota de bondes em 1901, consistiam em:

Dez carros-motores e quatro reboques puxados por locomotivas em dias de grande movimento; hoje, transformado um dos últimos, dispõe a Empreza de três reboques, onze carros-motores e o carro 'Amazonas' destinado ao Serviço do Governo do Estado. (DIÁRIO OFICIAL, 1901).

Os transportes por bondes, apesar de terem sua extensão interligada aos subúrbios, eram mecanismos criados com o objetivo de dar suporte à dinâmica capitalista, promovendo meio de acesso aos trabalhadores às áreas produtivas, porém com 
um princípio bastante significativo: refletir os critérios de identificação dos padrões de modernidade dos grandes centros, numa cidade dotada de todas as melhorias urbanas, sem, contudo, o aspecto público do serviço ser valorizado. Estes veículos consistiam no que havia de mais moderno em termos de deslocamentos, sendo, portanto, implantados com o objetivo de atender à elite que necessitava de meios de locomoção.

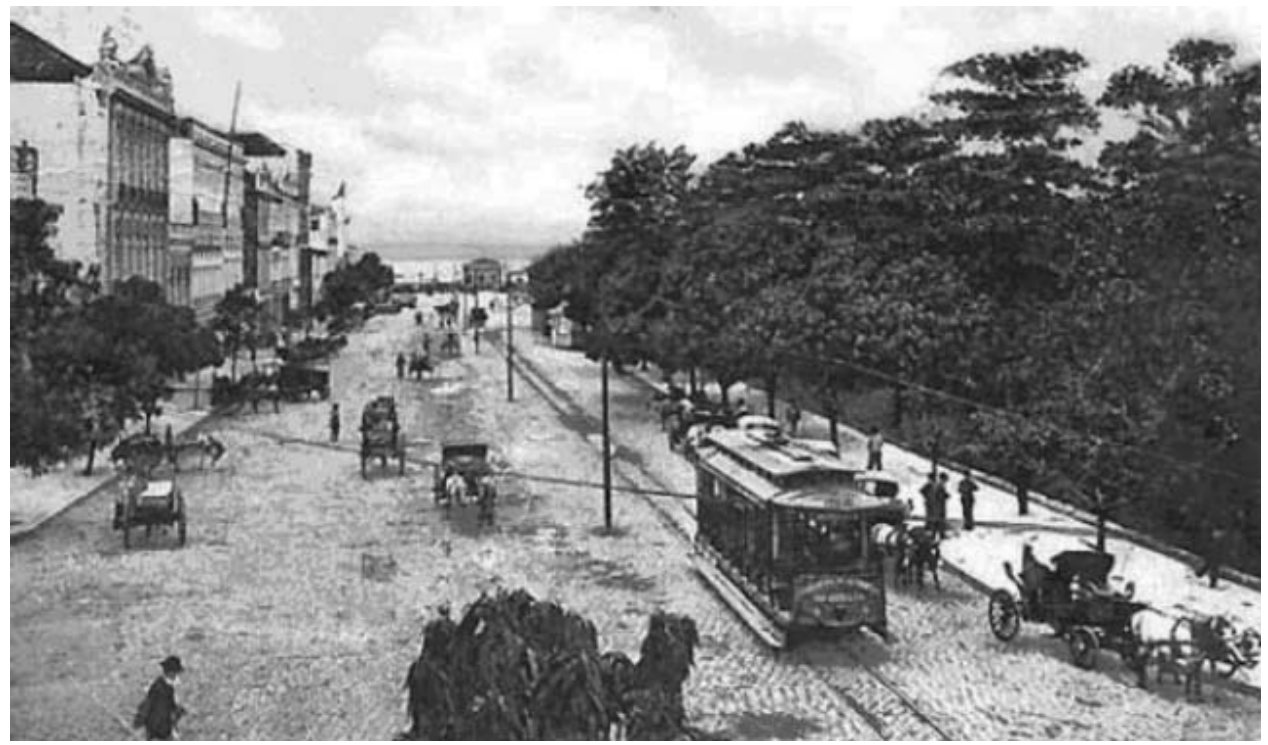

Figura 1. Bonde circulando pela avenida Eduardo Ribeiro, em direção ao Mercado e ao cais (1901-1902). Fonte: Foto/postal de Allen Morrison.

A cidade, que contara em 1848 com o montante de 3.640 habitantes, chegou a dispor de uma população em 1900, de perto de 50.300 habitantes (IBGE, 1980), decorrente da chegada não só de estrangeiros, mas também de milhares de nordestinos que passaram a ser a força utilizada na extração da borracha dos seringais e nos serviços urbanos, período em que o poder público se viu impulsionado a empreender a expansão urbana da cidade, dando prioridade ao sentido norte, fase em que os limites da capital estavam organizados da seguinte forma: na Zona Norte, localizavase a Vila Municipal, Mocó, Boulevard Amazonas e Flores; na Zona Leste, os bairros de Tocos, Plano Inclinado, circundados pelo igarapé de São Raimundo; ao sul, o perímetro central alardeado pelo rio Negro e, a oeste, a Cachoeirinha. Com exceção dos bairros de Educandos e São Raimundo, por serem circundados por igarapés (os

100 Somanlu, ano 9, n. 1, jan./jun. 2009 
moradores utilizavam as catraias para fazerem a travessia à zona central), os demais bairros dispuseram dos serviços de transportes por bondes elétricos, até mesmo os mais longínquos como Flores e outros, pois conforme salientou Oliveira:

\begin{abstract}
A implantação das primeiras linhas de bonde elétrico vieram facilitar a ocupação da parte leste, nordeste e norte da cidade, possibilitando a expansão da malha urbana para Cachoeirinha, Vila Municipal e Bilhares, arrabaldes para onde foram estendidos os trilhos. (OLIVEIRA, 1999. p. 100).
\end{abstract}

Após a euforia dos grandes investimentos, a cidade passou a experimentar nova realidade em termos econômicos, que circunstancialmente, levou à debandada de uma minoria da população, formada pela parcela próspera que partia, deixando expressa nos palacetes e casarões, ou nos aparatos urbanos implantados, os vestígios de sua presença. Nessa época, os serviços de transportes por bondes já estavam sob a responsabilidade da empresa inglesa Manáos Tramways and Light Company Ltda., que, desde 27 de abril de 1908, havia arrendado do engenheiro Antonio Lavandeyra a concessão dos serviços de viação, estendida também aos encargos do fornecimento de energia elétrica.

\title{
Crise econômica e dificuldades nos serviços de transportes coletivos
}

Foi em condições modestas que Manaus atravessou a década de 20, tendo sua receita descrita pelo governador Ephigênio Ferreira Salles como "estreitas, acanhadas condições do momento". (MENSAGEM, 1928, p. 9).

Quanto às condições urbanas da cidade, no que tange a administração da Manáos Tramways, em termos dos serviços elétricos e de bondes, o mesmo documento do governo afirmava que estavam sendo bem realizados, o que contradiz uma informação publicada no jornal Vida Operária, de 28 de março de 1920, que descreveu a concessionária, como "a hydra que asphixia o povo e as rendas do Estado, esse viveiro de indesejáveis, que carrega nos bolsos as leis brazileiras [...].” (VIDA OPERÁRIA, 1920). 


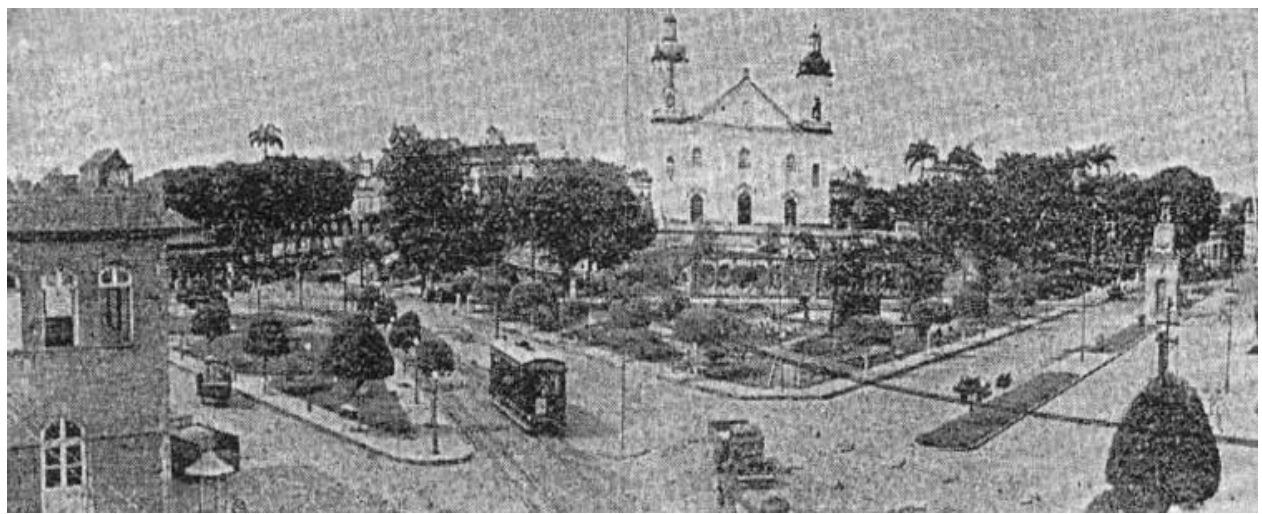

Figura 2. Praça Osvaldo Cruz, onde estacionavam os bondes.

Fonte: Acervo Fotográfico da EMTU. Imagem Recuperada/GEI/EMTU.

Descrevendo o quadro material da Manáos Tramways, o mesmo jornal comentou que a empresa não passava de: "[...] um antro de ruínas, que ameaça a vida de dezenas de operários e o pânico da população de Manáos.” (VIDA OPERÁRIA, 1920). Nos anos trinta a cidade permaneceu sem investimentos e poucos registros foram localizados destacando a situação dos transportes urbanos durante esse período.

O final dos anos 40 foi marcante para Manaus em termos de dificuldades, entre as quais a falta de energia elétrica, que deixou a cidade por vários meses às escuras, promovendo inviabilidade nas viagens por bondes. Por volta de 1946, a precariedade dos serviços era tão grande que em uma das paralisações, o interventor federal, em exercício, o sr. Raimundo Nicolau da Silva mandou colocar à "disposição do público todos os caminhões oficiais existentes na cidade, a fim de minorar a angustiosa situação dos transportes [...]" (OJORNAL, 1946)

A imprensa, ao longo de todo o período, representou a voz daqueles que utilizavam os transportes urbanos da cidade, expondo em várias notas o descontentamento que os habitantes viviam diante do desconforto e da inconstância dos serviços de bondes. Como a Tramways não se posicionava no sentido de investir na compra de veículos motorizados para colocá-los nas ruas, segundo Mavignier de Castro, em 1939 surgiu a primeira iniciativa de um particular em colocar essa modalidade de veículos em circulação, entretanto, a concessionária inglesa prontamente os comprou, sem fazê-los contribuir com o transporte de passageiros e, sim, para tirá-los de circulação, pois a empresa apenas "Os encostou na usina da Cachoeirinha onde não tardaram a transformar-se em sucata." (CASTRO, 1948, p. 72)

102 Somanlu, ano 9, n. 1, jan./jun. 2009 
Como a concessionária inglesa não interveio com a introdução de novos veículos para a circulação urbana da cidade, nem tampouco o poder público manifestava qualquer disposição em atender às reivindicações da população, gerando melhorias para esse segmento de serviços, a iniciativa privada, percebendo a lacuna deixada, fez, em 1947 a introdução dos veículos auto-ônibus, suprindo a defasagem causada pelos elétricos e permitindo com que aqueles que não possuíam condições de circular em veículos automóveis, dispusessem de uma nova experiência em termos de locomoção, começando assim outra fase nos deslocamentos urbanos da cidade de Manaus. Em contrapartida, os veículos que representaram por vários anos o símbolo de uma fase de desenvolvimento, constituindo orgulho referencial para os habitantes de Manaus, chegaram ao final dos anos 40 com seu maquinário desgastado, favorecendo, assim, a introdução de outra modalidade de serviços de locomoção, numa fase em que a idéia da implantação dos veículos automotivos se fortalecia.

O otimismo gerado nos primeiros tempos da implantação dos serviços de ônibus em Manaus foi substituído por frustração, motivado principalmente pelos custos dos serviços que a população se via obrigada a pagar para utilização de veículos em péssimo estado de conservação, pois os carros novos inseridos para o transporte de passageiros rapidamente ficavam danificados em vista das condições das vias de circulação.

No início dos anos 50, ainda havia os bondes, contudo, as ameaças de paralisação dos serviços se intensificaram durante o ano de 1952, sob a justificativa da falta de recursos, inclusive para o pagamento da lenha para seu funcionamento, fato destacado, em 7 de agosto de 1952, pelo jornal que sentenciava:

Agrava-se o problema de luz. Ontem ocorreu uma notícia de que o tráfego dos bondes, por medida de economia, seria paralisado em caráter definitivo, disse o engenheiro Leopoldo Loureiro que não cogita do assunto no momento. Parar os bondes é muito fácil, mas não resolverá a situação. Parados os bondes, desaparecerá naturalmente a sua ínfima receita. A receita com pessoa do tráfego, motorneiros, cobradores, etc., permanecerá a mesma.O assunto poderia ser cogitado pelo governo, desde que dispusesse de nunca menos de Cr\$ 1.000.000,00 para proceder à indenização de seus operários, mas se não há dinheiro, nem para pagar a lenha para o serviço de luz, como olhar o assunto agora (DIÁRIO DA TARDE, 1952). 
Apesar de declaração negativa prestada por Leopoldo Loureiro, engenheiro responsável pelas atividades de viação nesse período, os bondes pararam de trafegar e a população pobre e dependente dos serviços passou a enfrentar maiores dificuldades.

Envolta nos problemas estruturais que, ao longo dos anos abalaram a economia do Estado, Manaus chegou à segunda fase da década de 50, marcada pelas ações do governo trabalhista de Plínio Coelho. Assumindo a administração pública com grande aprovação popular, o governador conseguiu ajustar uma série de pendências advindas da administração passada, restabelecendo principalmente o crédito do Estado, bem como implementando melhorias para a região, sob a influência das diretrizes do Plano de Metas, do Governo de Juscelino Kubitschek, quando o País passou a receber maior abertura para o andamento da produção industrial.

Em 1955, o governador Plínio Coelho autorizou retornar ao tráfego algumas das linhas de bondes. Esta medida tinha por fim diminuir o quadro de dificuldades que se instalara na cidade em vista da dependência pelos veículos de transporte coletivo motorizado. Apesar de a tentativa da Inspetoria de Tráfego Público na normalização das atividades de circulação, os proprietários dos veículos imprimiam ações de forma desregulamentada, não atendendo ao cumprimento de horários e reivindicando periodicamente aumento no preço das passagens, gerando um quadro de revolta nos usuários que reclamavam que os preços das passagens não convinham com a qualidade dos serviços.

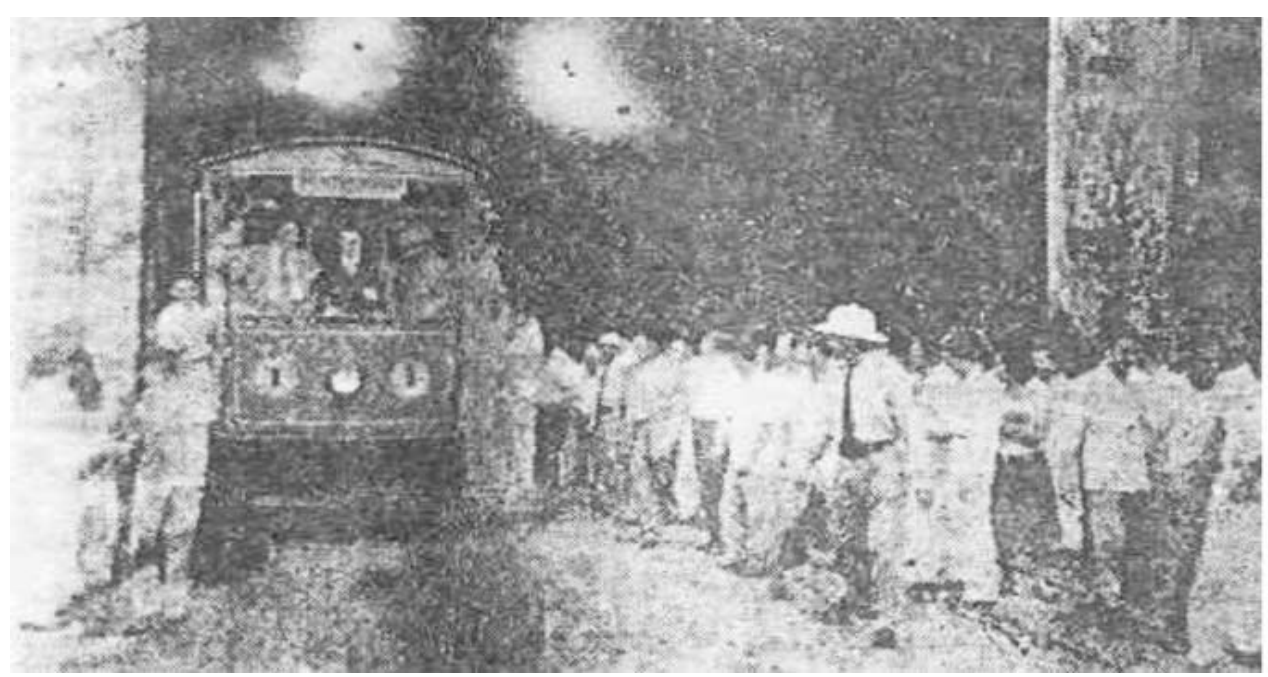

Figura 3. Em 1955, nova inauguração das linhas de bonde tendo o governador Plínio Coelho dirigido um dos veículos. Fonte: Acervo de jornais da Biblioteca Pública do Estado.

104 Somanlu, ano 9, n. 1, jan./jun. 2009 


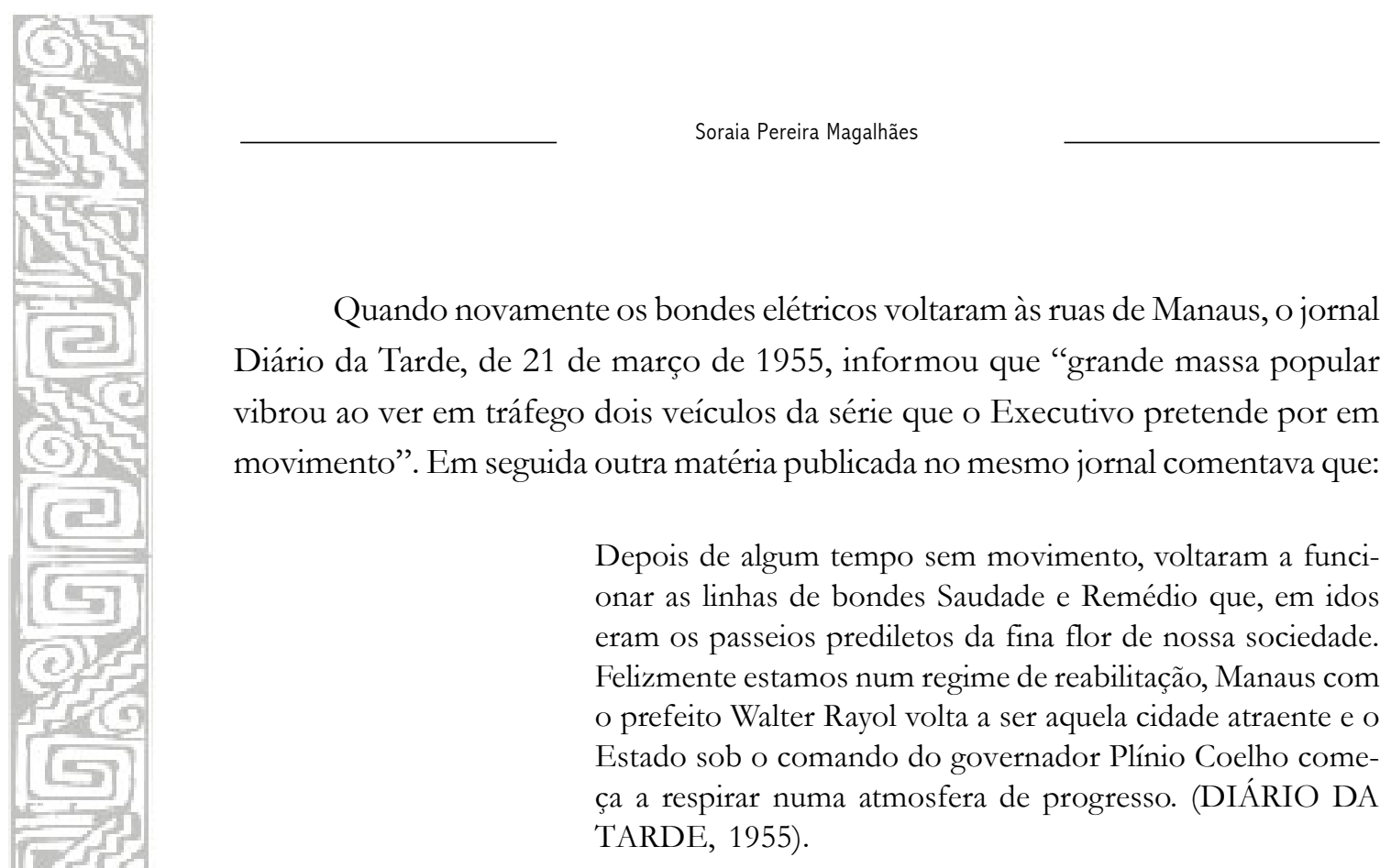

Se a iniciativa em estabelecer ao tráfego algumas das linhas de bondes não trouxe melhorias para a locomoção urbana de Manaus, as críticas diárias, decorrentes da instabilidade desses veículos e dos serviços realizados pelos proprietários dos ônibus e lotações de madeira, repercutiam nos jornais a insatisfação dos usuários que esperavam do poder público uma solução ante ao caótico quadro, que se apresentava de difícil solução.

Nessas condições, surgiu, por parte do Estado, a ideia para a criação de uma empresa de economia mista, a Transportamazon, que além trazer a proposta de uma nova dinâmica para o transporte coletivo urbano, atenderia a outros segmentos de circulação, numa perspectiva que se voltava para os desígnios de uma nova conjuntura, que se inclinava a dimensões mais amplas voltadas para a modernização do País. Em vista da nova proposta os velhos veículos rangedores foram definitivamente retirados de circulação.

\section{Considerações finais}

Os bondes fizeram parte da vida urbana da cidade de Manaus por várias décadas, talvez por isso seja a categoria de veículos que permanece na memória e no imaginário de muitos como um serviço de qualidade, um serviço que deixou saudade. Contudo, muitas das informações coletadas sobre o período apontam aspectos contraditórios desse ideário.

Somanlu, ano 9, n. 1, jan./jun. 2009105 
Várias foram as irregularidades observadas na prestação dos serviços de transportes por bondes; das críticas, podemos citar atrasos na frequência de viagens, mau atendimento prestado pelos profissionais em serviços, barulho provocado pela circulação dos carros nos trilhos, má conservação dos veículos, acidentes e outros. Esses fatores nos levam a compreender que os habitantes de Manaus daquele período conviveram com problemas semelhantes aos que hoje povoam os noticiários sobre os serviços realizados por ônibus. Apesar das reclamações constantes, contudo a população deve ter sentido os efeitos da retirada dos antigos bondes elétricos. O desabafo deixado por Almeida Barroso em 19 de agosto de 1952, sobre a ação do poder público em determinar a suspensão das atividades operacionais dos veículos reflete um pouco da insatisfação que deve ter sido extensiva a muitos usuários:

Hoje desapareceu o bonde para a cidade noturna. Em compensação e talvez por vingança, foi-se a vida noturna da cidade. Mas a fúria homicida - diria bondicida é irrefreável. Daí a intenção de alguns homens públicos, talvez insensatos, de acabar de uma vez por todas com os bondes. Não temem esses insensatos, que se isso acontecer os bondes se vinguem mais uma vez contra Manaus, que sempre foi tão deles quanto nossa? Seria bom pensarem nisso. (A CRÍTICA, 1952).

Em vista do serviço de transporte coletivo ser objeto tão essencial para aqueles que deles se utilizam, mesmo quando não atinge um nível de satisfação adequado, os usuários hesitam em perdê-lo. Foi assim no caso dos bondes, é assim nos dias atuais quando o poder público estabelece a retirada de uma linha de ônibus, um ponto de parada, um quadro de horário ou qualquer outro benefício já implantado. No campo das necessidades urbanas e em se tratando da ação dos deslocamentos, quanto mais serviços estão disponibilizados maiores são as possibilidades do atendimento dos anseios da coletividade.

Os bondes encerraram suas atividades em Manaus em 1957 praticamente sem registros. $\mathrm{O}$ fato do poder público investir nesse período na compra de ônibus modernos para a composição da frota da Transportamazon, empresa que seria administrada pelo Estado deve ter contribuído para esse esquecimento.

Diante do exposto, torna-se válido apontar um grave fator esquecido pelo poder público nos parâmetros dos transportes coletivos em Manaus: a falta de uma

106 Somanlu, ano 9, n. 1, jan./jun. 2009 


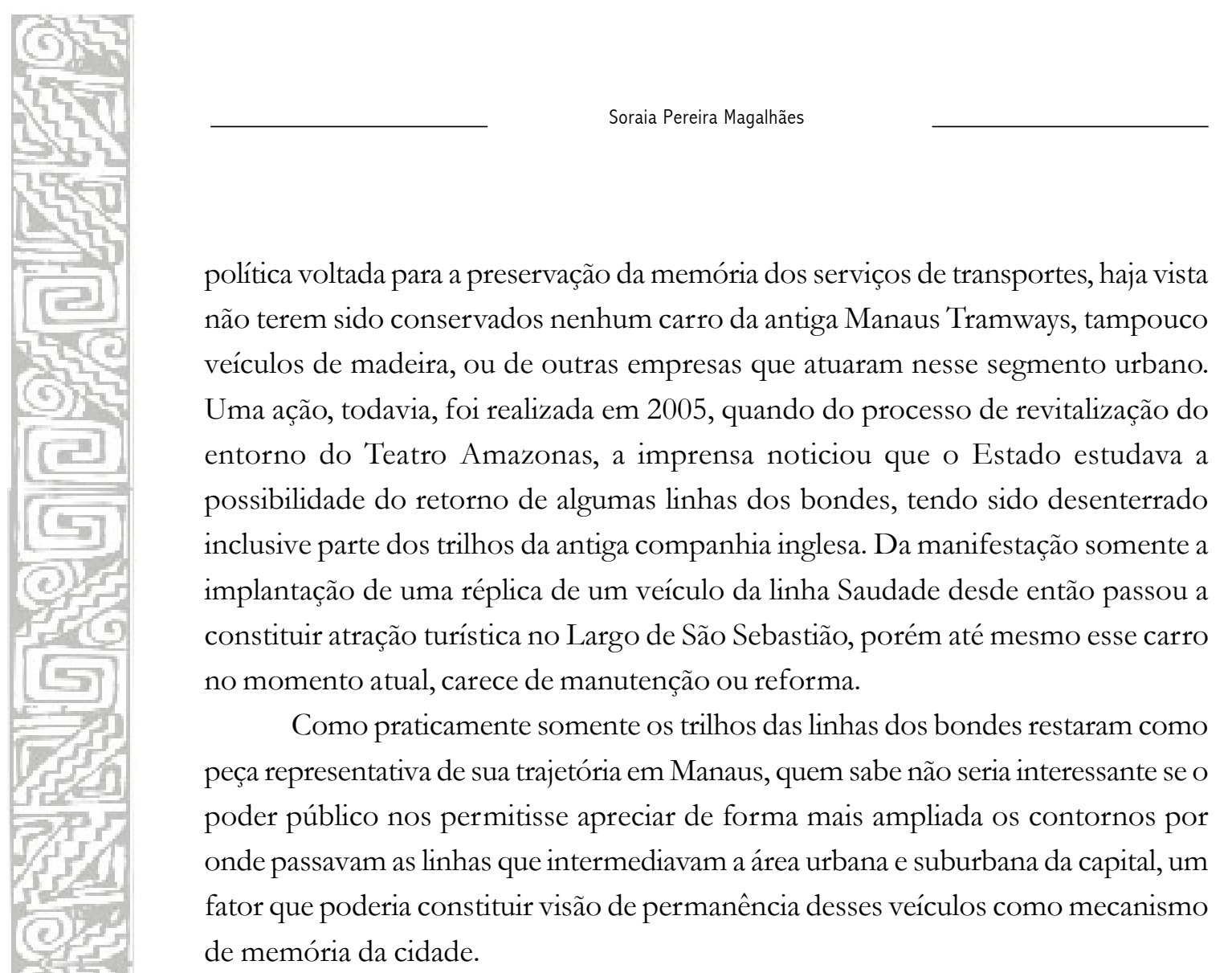

política voltada para a preservação da memória dos serviços de transportes, haja vista não terem sido conservados nenhum carro da antiga Manaus Tramways, tampouco veículos de madeira, ou de outras empresas que atuaram nesse segmento urbano. Uma ação, todavia, foi realizada em 2005, quando do processo de revitalização do entorno do Teatro Amazonas, a imprensa noticiou que o Estado estudava a possibilidade do retorno de algumas linhas dos bondes, tendo sido desenterrado nclusive parte dos trilhos da antiga companhia inglesa. Da manifestação somente a con constituir atração turística no Largo de São Sebastião, porém até mesmo esse carro no momento atual, carece de manutenção ou reforma.

Como praticamente somente os trilhos das linhas dos bondes restaram como peça representativa de sua trajetória em Manaus, quem sabe não seria interessante se o poder público nos permitisse apreciar de forma mais ampliada os contornos por onde passavam as linhas que intermediavam a área urbana e suburbana da capital, um de memória da cidade.

\section{Referências}

AMAZONAS. Leis. Decretos e Regulamentos. Colleção das Leis de 1882.

. Mensagem: em janeiro de 1898, pelo exmo. sr. governador Fileto Pires Ferreira. Manáos: Imprensa Official, 1898. p. 33.

. Mensagem: lida perante o Congresso dos Senhores Representantes em 1. de Março de 1896, pelo exmo. sr. Governador Eduardo Gonçalves Ribeiro. Manáos: Imprensa Official, 1897, p. 28.

- As linhas. Diário Oficial, 3 de maio de 1901. Superintendência Geral de Fiscalização. Relatório dos serviços por electricidade. Manáos, 1901.

- Mensagem apresentada pelo Presidente do Estado do Amazonas Ephigênio Ferreira Salles à Assembleia Legislativa e lida na abertura da 3. ${ }^{a}$ Sessão ordinária da 13. ${ }^{a}$ Legislatura. Manaus, 1928, p. 9. 
Lei n. ${ }^{\circ} 11$ de 21 de março de 1957. Administração do Dr. Plínio Ramos Coelho, governador do Estado. Autoriza o chefe executivo a fundar uma sociedade de economia mista para a solução do transporte no seu tríplice aspecto.

AMAZONAS. Mensagem do governador Plínio Ramos Coelho à Assembleia Legislativa apresentada na primeira Sessão Legislativa de 1963. Imprensa Oficial, 1963, p. 6.

Comércio do Amazonas, 26 de outubro de 1899.

MANÁOS Tramways. Vida operária, 28 de março de 1920, p. 1, rolo 11.

OS BONDES não trafegaram e os caminhões oficiais e particulares transportarão os habitantes dos subúrbios. O Jornal, 3 de julho de 1946, p. 1.

ÔNIBUS para Manaus. Jornal do Comércio, 29 de julho de 1947.

SURGIRÁ nas ruas o ônibus “Zepelim”. Jornal do Comércio, 29 de junho de 1948.

NOVA ameaça paira sobre o serviço de bondes... Diário da Tarde, 19 de março de 1952.

NÃO há lenha. Não há lenha porque não há dinheiro para pagar aos fornecedores. $\mathrm{O}$ tráfego de bondes. Diário da Tarde, 7 de agosto de 1952.

BONDES. A Crítica, 19 de agosto de 1952.

MARCADA para amanhã a inauguração dos ônibus Zepelins. Diário da Tarde, 15 de outubro de 1955

SALVE os bondes das linhas Saudade e Remédios. Diário da Tarde, 6 de junho de 1955.

DEZ novos ônibus. A Crítica, 10 de julho de 1957.

TRANSPORTE gratuito. A tarde, 25 de junho de 1957.

INICIA hoje a "Transportamazon" o Serviço de Transporte Coletivo. A Crítica, 31 de dezembro de 1957.

AB'SABER, Aziz Nacib. A cidade de Manaus: primeiros estudos. Boletim Paulista de Geografia. n. 15, São Paulo, 1953.

108 Somanlu, ano 9, n. 1, jan./jun. 2009 


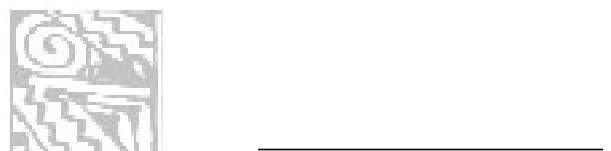

Soraia Pereira Magalhães

AGUIAR, José Vicente de Souza. Manaus: praça, café, colégio e cinema nos anos 50 e 60. Manaus: Editora Valer, 2002.

AMAZONAS, Claúdio. Memórias do alto da Bela vista: roteiro sentimental de Educandos. Manaus: Norma, propaganda e marketing. Educandos, 1996.

ANDRADE, Moacir. Santa Doroteia: 1910 a 1995. Manaus: [s.n.], 1995.

ARAÚJO, André Vidal. Sociologia de Manaus: aspectos de sua aculturação. Manaus: Fundação Cultural do Amazonas, 1994.

ASSOCIAÇÃO NACIONAL DOS TRANSPORTES URBANOS NO BRASIL (NTU). Cem anos do transporte urbano no Brasil. São Paulo: Revista Technobus, 1997.

BITTENCOURT, Agnello. Chorographia do Estado do Amazonas. Reprodução facsimilada da edição de 1925. Manaus: ACA-Fundo Editorial, 1985.

BRASILEIRO, Anísio \& HENRY, Etienne. Ônibus das cidades brasileiras. São Paulo: Editores Associados, 1999.

BURNS, E. Bradford. Manaus, 1910: retrato de uma cidade em expansão. Manaus: Ed. Governo do Estado, 1966.

CASTRO, Mavignier de. Sintese histórica e sentimental da evolução de Manaus. Manaus: Tipografia Fênix, 1948.

CD ROM Projetos arquitetônicos do início do século. Governo do Estado do Amazonas, 2000.

CORRÊA, Luiz de Miranda. Guia de Manaus: roteiro histórico e sentimental da cidade do Rio Negro. Rio de Janeiro, 1969.

COSTA, Francisca Deusa Sena da. Quando viver ameaça a ordem urbana: trabalhadores urbanos em Manaus (1890-1915). Dissertação de Mestrado em História apresentado a Pontifícia Universidade Católica PUC. São Paulo, março, 1997.

COSTA, Selda Vale da. Eldorado das ilusões cinema \& sociedade: Manaus (1897-1935). Manaus: Editora da Universidade, 1996.

DIAS, Edinéa Mascarenhas. A ilusão do fausto: Manaus 1890-1920. Manaus: Valer, 1999.

ECKARDT, Wolf Von. A crise das cidades. Rio de Janeiro: Zahar Editores, 1975.

Somanlu, ano 9, n. 1, jan./jun. 2009109 
FUNDAÇÃO JOÃO PINHEIRO. Uma história dos transportes coletivos em Belo Horizonte. Belo Horizonte, 1996.

GARCIA, Etelvina. O ganso do Capitólio. Etelvina Garcia. Série Memória, n. 74. Manaus: Secretaria de Estado da Cultura, Turismo e Desporto, 2001.

IBGE. Anuário Estatístico do Brasil, 1980.

ITUASSÚ, Oyama César. Memórias do men tempo. Manaus: Edição do autor, 1998.

LOUREIRO, Antônio José Souto. A grande Crise. (1908-1916). Manaus: T. Loureiro, 1985.

MAGALHÃES, Soraia; LIMA, Gisele da Silva. Bondes em Manaus. Revista dos Transportes Públicos, São Paulo, ano 22, n. 88, 3. trim., p. 91-101, 2000. 2000. . Bondes em Manaus. Série Memória, n. 12. Governo do Amazonas: Manaus,

MATA, João Nogueira da. Antiqualhas manauaras. Manaus: Umberto Calderaro, 1991. MELLO, Gilberto de. A história do bonde. Revista dos Transportes Públicos. São Paulo, ano 21, n. 82, 1. trim., p. 117-122, 1999.

MELLO, Thiago de. Manaus: amor e memória. Rio de Janeiro: Philobiblion, 1984.

MESQUITA, Otoni Moreira de. Manaus: história e arquitetura (1852-1910). Manaus: Editora da Universidade do Amazonas, 1997.

MONTEIRO, Mário Ypiranga. Fundação de Manaus. Manaus: Conquista, [s. d.]

Negritude e Modernidade. Manaus: Imprensa Oficial, 1990.

OLIVEIRA, José Aldemir de. Manaus, permanências e transformações: 1920-1967. Relatório de pesquisa apresentado à Secretaria de Estado da Cultura e Estudos Amazônicos como parte do projeto "Busca da Identidade", Manaus, 1999.

PACHECO, Leila Maria Serafim. A informação enquanto artefato. Informare, Rio de Janeiro, v. 1. n. 1, p. 21-24, jan./jun, 1995.

PIRES, José Jeferson Carpinteiro. Evocação de Manaus. como eu a vi ou sonhei. Manaus: Imprensa Oficial, 1984.

110 Somanlu, ano 9, n. 1, jan./jun. 2009 


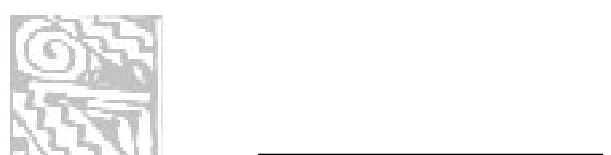

Soraia Pereira Magalhães

PINHEIRO, Maria Luiza Ugarte. A cidade sobre os ombros: trabalho e conflito no porto de Manaus (1889-1925). Manaus: Ed. da Universidade do Amazonas, 1999.

REIS, Arthur C. Ferreira. Como governei o Amazonas. Manaus: Governo do Estado do Amazonas, 1967.

RIOS, Gilvando Sá Leitão. Linhas apagadas: do coletivo como arcaico ao individual como moderno, a extinção dos bondes na década de 40. João Pessoa, 1995.

SOMBRA, Raimundo Nascimento. Fundamentos de bistória e geografia do Amazonas. Manaus: Prisma, 1996.

STIEL, Waldemar Corrêa. História do transporte urbano no Brasil: bondes e trolebus. São Paulo: Pini, 1984.

WRITE, Charles Leslie. O que é transporte urbano. São Paulo: Brasiliense, 1988. (Coleção Primeiros Passos.). 